\title{
Mechanism of accommodation: A review of theoretical propositions
}

\begin{tabular}{|c|c|}
\hline \multicolumn{2}{|c|}{$\begin{array}{l}\text { Authors: } \\
\text { Godwin O. Ovenseri- } \\
\text { Ogbomo } \\
\text { Olalekan A. Oduntan }\end{array}$} \\
\hline \multicolumn{2}{|c|}{$\begin{array}{l}\text { Affiliations: } \\
{ }^{1} \text { Department of Optometry, } \\
\text { University of KwaZulu-Natal, } \\
\text { South Africa }\end{array}$} \\
\hline \multicolumn{2}{|c|}{$\begin{array}{l}{ }^{2} \text { Department of Optometry, } \\
\text { University of Benin, Nigeria }\end{array}$} \\
\hline \multicolumn{2}{|c|}{$\begin{array}{l}\text { Correspondence to: } \\
\text { Godwin Ovenseri-Ogbomo }\end{array}$} \\
\hline \multicolumn{2}{|c|}{$\begin{array}{l}\text { Email: } \\
\text { godwin.ovenseri-ogbomo@ } \\
\text { uniben.edu }\end{array}$} \\
\hline \multicolumn{2}{|c|}{$\begin{array}{l}\text { Postal address: } \\
\text { Department of Optometry, } \\
\text { Faculty of Life Sciences, } \\
\text { University of Benin, PMB } \\
\text { 1125, Benin City, Nigeria }\end{array}$} \\
\hline \multicolumn{2}{|c|}{$\begin{array}{l}\text { Dates: } \\
\text { Received: } 22 \text { Oct. } 2014 \\
\text { Accepted: } 31 \text { Mar. } 2015 \\
\text { Published: } 17 \text { Sept. } 2015\end{array}$} \\
\hline \multicolumn{2}{|c|}{$\begin{array}{l}\text { How to cite this article: } \\
\text { Ovenseri-Ogbomo GO, } \\
\text { Oduntan OA. Mechanism of } \\
\text { accommodation: A review } \\
\text { of theoretical propositions. } \\
\text { Afr Vision Eye Health. } \\
\text { 2015;74(1), Art. \#28, } 6 \text { pages. } \\
\text { http://dx.doi.org/10.4102/ } \\
\text { aveh.v74i1.28 }\end{array}$} \\
\hline \multicolumn{2}{|c|}{$\begin{array}{l}\text { Copyright: } \\
\text { (C) 2015. The Author(s). } \\
\text { Licensee: AOSIS } \\
\text { OpenJournals. This work is } \\
\text { licensed under the Creative } \\
\text { Commons Attribution } \\
\text { License. }\end{array}$} \\
\hline \multicolumn{2}{|l|}{ Read online: } \\
\hline 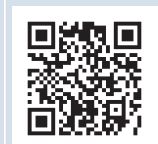 & $\begin{array}{l}\text { Scan this QR } \\
\text { code with your } \\
\text { smart phone or } \\
\text { mobile device } \\
\text { to read online. }\end{array}$ \\
\hline
\end{tabular}

Accommodation is the process by which the human eye changes its focus to see objects at varying distances from the eye. For nearly 300 years, scientists have investigated and presented various views on the mechanism of accommodation. The purpose of this review is to present both the historical and contemporary theories that underpin the process of accommodation. Keywords such as ocular accommodation, mechanism of accommodation and accommodative mechanism were used to retrieve published material on the subject. Classical propositions by Thomas Young and Hermann von Helmholtz, amongst others, are presented.

\section{Introduction}

The human eye has the ability to see clearly objects placed at varying distances from it. This phenomenon was reported to have been first demonstrated by Scheiner ${ }^{1,2}$ in 1619 , using a double pinhole. When a target was viewed monocularly through a double pinhole in a card, the target was seen singly. When a second target located closer to the eye than the first was viewed, the second target appeared double, requiring a change in the eye's dioptric power to see the second target singly. This classic experiment by Scheiner showed that the normal human eye cannot focus on a near and distant target simultaneously. A change in focus is required to see objects at varying fixation distances. According to Atchison and Charman ${ }^{3}$, Potterfield ${ }^{4}$ in 1738 was credited with the term 'accommodation' to describe the focusing ability of the human eye over a range of distances.

In recent times, accommodation has been defined in various ways. According to Hofstetter et al. ${ }^{5}$ and Ciuffreda, ${ }^{6}$ accommodation is the process by which the dioptric power of the crystalline lens is increased to bring the image of a near object to focus on the retina. Keirl ${ }^{7}$ described positive accommodation as referring to the increase in the dioptric power of the eye to focus from distance to near, and negative accommodation as referring to the decrease in dioptric power to focus from near to distance. Accommodation has also been described as 'focusing of the eye on a near object through relaxation of the ciliary muscle and thickening of the lens' ${ }^{8}{ }^{8}$ Grosvenor ${ }^{9}$ defines accommodation as 'the process by which the crystalline lens varies its focal length in response to changes in the vergence of incident light'. Glasser ${ }^{10}$ defines accommodation as a 'dynamic, optical change in the dioptric power of the eye allowing the point of focus of the eye to be changed from distance to near objects'. These definitions are consistent in indicating that a change in the dioptric power of the crystalline lens is implicated in the process of accommodation.

\section{Structural basis for accommodation}

Historically, there have been various propositions regarding the anatomical structures and physiological processes that underpin the ability of the eye to adjust focus in order to see objects at varying distances. Ciuffreda ${ }^{6}$ itemised some of the proposed mechanisms for the eye's ability to see objects at varying distances. Given that cornea curvature accounts for over $75 \%$ of the refractive power of the human eye, it was thought that a change in corneal curvature could account for this focusing ability. ${ }^{6,11}$ According to Atchison and Smith, ${ }^{12}$ a $4 \mathrm{D}$ accommodative response could be achieved by a reduction in corneal radius of curvature of about $0.7 \mathrm{~mm}$ or an increase in axial length of about $1.5 \mathrm{~mm}$. Young ${ }^{13}$ refuted this proposition by noting that when he immersed his eyes in water, thereby neutralising the refracting power of the eye, he was still able to elicit accommodation. Anterior axial movement of the crystalline lens has also been considered to play a role in the accommodative process. This notion of anterior axial movement of the crystalline lens during accommodation was attributed to Johannes Mueller, when he described the circular muscle of the iris in $1854 .{ }^{14}$ Other anatomical actions that have been considered to play a role in accommodation include a change in the axial length of the eye, contraction of the pupil, and an increase in the depth of focus of the eye. ${ }^{6}$ Even before the term 'accommodation' was coined by Potterfield in 1738, Descartes ${ }^{15}$ had speculated that changes in the refractive power and shape of 
the crystalline lens might be responsible for the ability of the human eye to see objects at varying distances.

In his classic experiments, Thomas Young conclusively demonstrated, by inference, that the ability of the eye to adjust focus for varying distances results from an increase in the curvature of the crystalline lens. ${ }^{13}$ While presenting the Bakerian Lecture before the Royal Society in 1801, Young (amongst other issues) discussed his experiments on the accommodation of the eye. In ruling out change in the curvature of the cornea, Young noted that a decrease of $19 \%$ in the curvature of the cornea would be needed to account for his $10 \mathrm{D}$ amplitude of accommodation. Furthermore, he concluded that accommodation does not alter the shape and radius of curvature of the cornea, which he arrived at by observing that the size of the image reflected from the cornea (Purkinje image No I) does not change with accommodation. In addition, Young also reported the occurrence of accommodation when the corneal refractive power was neutralised by immersing the eye in water. To account for the $10 \mathrm{D}$ of accommodation, Young calculated that there needed to be a $3.43 \mathrm{~mm}$ increase in axial length. However, he reported an experiment in which there was no noticeable change in axial length during active accommodation. ${ }^{13}$ He thus ruled out the possibility of increase in axial length playing a role in accommodation. ${ }^{6,9}$

Consequently, by excluding other hypotheses for accommodation, Young suggested that the crystalline lens was in fact responsible for ocular accommodation. To substantiate this assertion, he reported that an aphakic eye could not accommodate for near distances. Although there were reports of accommodation being present in the socalled 'lensless' eye, , $^{16,17,18}$ these assertions were regarded to be based on depth of focus and not accommodation.

\section{Mechanism of accommodation}

Having laid to rest the argument as to which anatomical structure is responsible for accommodation, following Young's classic experiment, the next stage was to establish the precise mechanism for accommodation. No doubt there were several explanations for the mechanism of accommodation. One notable early theory of the mechanism of accommodation was proposed by Cramer. ${ }^{19}$

\section{Cramer's vitreous theory}

Following Purkinje's discovery of the reflected images of a candle from the anterior and posterior surfaces of the crystalline lens in 1823, Cramer in 1853 measured the Purkinje image during accommodation ${ }^{19}$ and noted that the image became smaller during accommodation. He further observed that the anterior surface of the crystalline lens became more convex whilst the posterior surface did not change in shape. Following his observation, Cramer proposed a theory for accommodation suggesting that, during accommodation, the ciliary muscle contraction acted on the choroid which in turn compressed the vitreous against the posterior crystalline lens. The iris resists the subsequent lens pressure, and the anterior surface of the crystalline lens in the pupillary area increases in curvature. This theory was refuted later when accommodation was demonstrated in a patient with aniridia. ${ }^{20}$ The proposition, however, supported Young's conclusion that the crystalline lens was responsible for accommodation of the eye.

Subsequently, there were several explanations for the mechanism of accommodation; however, there are two classic and opposing theories of accommodation, one proposed by von Helmholtz in 1855 and the other by Tscherning in 1909. In the present paper, these two theories as well as recent theoretical propositions for the mechanism of accommodation which are more or less modifications of these two classic ones are reviewed.

\section{Helmholtz's relaxation theory of accommodation}

Helmholtz ${ }^{21,22}$ proposed his relaxation theory of accommodation utilising the change in the size of the Purkinje image on the anterior surface of the crystalline lens (similar to Cramer's experiment) to support the idea that the crystalline lens is indeed responsible for accommodation. He observed that when the eye is in the unaccommodated state and focused for distance, the ciliary muscle is relaxed and the elastic zonular fibres are in a state of tension, pulling the crystalline lens outwards at the equator and maintaining the lens in a somewhat flattened state. He further observed that during accommodation, the ciliary muscle contracts, causing a reduction in the zonular tension that allows for the increase in curvature of the crystalline lens, a decrease in its equatorial diameter, and increased lens thickness; an increase in the curvature of the anterior surface of the crystalline lens with only a small change in the curvature of the posterior surface of the crystalline lens; a forward movement of the anterior surface of the crystalline lens whilst the posterior surface showed no appreciable movement; and an increase of $0.5 \mathrm{~mm}$ in the axial thickness of the lens during accommodation. Given that the lens volume is constant, ${ }^{23}$ Helmholtz concluded that the lens equatorial diameter decreased during accommodation. Helmholtz's relaxation theory of accommodation has received support and modifications from other researchers.

Gullstrand $^{24,25}$ suggested that, besides capsular elasticity accounting for accommodation of the crystalline lens, there are changes in the intracapsular forces that contribute to the accommodative process. Gullstrand further modified Helmholtz's theory of accommodation to include the elastic force of the choroid as the restoring force to ciliary muscle contraction..$^{22}$

By noting that amplitude of accommodation was normal in aniridia, Fincham ${ }^{20}$ debunked the role of the iris in Helmholtz's relaxation theory. He further observed that when the capsule of the crystalline lens was removed, the lens assumed its unaccommodated shape, and he concluded that the capsule 
was responsible for the elasticity of the crystalline lens. He concluded that during accommodation, the lens substance is moulded into an accommodated form by the elastic capsule. $\mathrm{He}$ also described the regional variation of the thickness of the lens capsule. He reported that the lens capsule was thicker at the peripheral surfaces than the central polar surface and showed how this variation allowed the lens poles to become steeper in curvature than the peripheral surfaces, such that the crystalline lens assumed a coniodal form. Fisher ${ }^{26}$ and Fisher and Pettet ${ }^{27}$ have questioned this regional variation as a possible mechanism for accommodation. The lens capsule did not have the thickness observed by Fincham until advancing age after the eye was capable of accommodation. ${ }^{26}$ Fisher $^{26}$ also showed that the strength of the lens capsule and the intraocular pressure of the eye were not adequate to allow the changes in the crystalline lens to occur by this mechanism. There was also the question of the anterior crystalline lens surface bulging more than the posterior surface despite the anterior surface being thicker than the posterior surface. Coleman ${ }^{28}$ suggested that the bulge of the posterior surface was countered by the vitreous, and hence the anterior lens surface would become more curved with accommodation than the posterior surface.

Studying the age dependence of the optomechanical responses of the human lens, Manns et al. ${ }^{29}$ and Augusteyn et $a .^{30}$ concluded that their experimental findings were consistent with the theory of accommodation proposed by Helmholtz. ${ }^{22}$ Experimental results from the two studies showed that the force required to de-accommodate the lens increases with age, which is consistent with the theory of presbyopia which is based on the Helmholtz theory. Wan and $\operatorname{Ravi}^{31}$ derived a mathematical model to account for the Helmholtzian theory of accommodation. They stated that their results were consistent with the theory of accommodation proposed by Helmholtz, notwithstanding the assumptions made in deriving the model. Finite element modelling of a 30-year-old lens has also been used to provide evidence for Helmholtz's theory of accommodation..$^{32}$ Basing their model on the Helmholtz theory of accommodation, they demonstrated that the lens nucleus and cortex became stiffer with increasing age, thus requiring more force to reshape the lens to its unaccommodated state. Glasser et al. ${ }^{33}$ showed that the diameter of the crystalline lens of monkeys decreased by as much as an average of $7.04 \%$ (similar to the $7.44 \%$ decrease reported by Wilson ${ }^{34}$ in accordance with the mechanism of accommodation proposed by Helmholtz and in contrast with Tscherning's theory). Using magnetic resonance imaging (MRI) in young and older human emmetropic subjects, Kasthurirangan et al. ${ }^{35}$ demonstrated accommodative changes in the crystalline lens that were consistent with Helmholtz's theory of accommodation. They showed an increase in lens thickness, a decrease in anterior chamber depth, a decrease in lens equatorial diameter, a decrease in the radius of curvature of the posterior lens surface, and a decrease in the ciliary ring diameter. Similar results were also obtained by Wilson $^{34}$ and Jones et al. ${ }^{36}$ Wilson described a new technique with which he measured the diameter of the lens during accommodation. Using infrared retro-illumination video photography and pixel measurements, Wilson ${ }^{34}$ showed that during accommodation there is a reduction in the lens diameter from an average of 524 pixel units in the relaxed eye to 485 pixel units during accommodation. Similarly, Jones et al..$^{36}$ using MRI showed that during accommodation there is an increase in lens thickness of $0.05 \mathrm{~mm}$ and a decrease in diameter of $-0.067 \mathrm{~mm}$ per dioptre of accommodation. These findings are also consistent with Helmholtz's theory of accommodation.

\section{Tscherning's zonular contraction theory}

Completely disagreeing with Helmholtz's theory of accommodation, Tscherning ${ }^{37}$ suggested an opposing theory. Tscherning used an ophthalmophacometer that he had constructed to observe the images formed on the anterior and posterior surface of the crystalline lens (Purkinje image III and IV). He proposed that ciliary muscle contraction increases the tension on the zonules, thereby altering the shape of the lens without changing its thickness or diameter ${ }^{20,37}$ (as cited by Strenk et al. ${ }^{38}$ ). It was Tscherning's position that when the crystalline lens is removed from the eyeball, it is adjusted for distant vision and not accommodated as Helmholtz had suggested. With increasing evidence showing that the crystalline lens increases in diameter and thickness, Tscherning modified his theory and conceded that crystalline lens thickness increases during accommodation, but he held that ciliary muscle contraction causes increased zonular traction. According to the second theory, the zonular traction would cause the crystalline lens to become flattened at its periphery during accommodation, with an associated bulging of the central pupillary zone. He attributed this anterior bulge of the crystalline lens to the differential mechanical properties of the lens cortex and nucleus. ${ }^{39,40}$ Tscherning's theory was modified by Pflugk, who considered the role of the vitreous in the process of accommodation. ${ }^{41,42}$

Tscherning's theory that the diameter of the crystalline lens increases has been disproved by various investigators. Wilson $^{34}$ stated that Tscherning could not prove his theory of increased lens diameter in his lifetime. Wilson measured the diameter of the crystalline lens using infrared retroillumination video photography and found that the diameter of the lens decreases from an average of 524 to 485 pixel units in the unaccommodated and accommodated states respectively, representing a $7.44 \%$ decrease. He concluded that Tscherning's theory and all other theories which indicate that the lens diameter increases during accommodation are incorrect. Wilson and other researchers ${ }^{20,43,44}$ have variously demonstrated that the diameter of the crystalline lens decreases during accommodation as proposed by Helmholtz, as opposed to Tscherning's theory. Additionally, Glasser et al. ${ }^{33}$ showed a $7.04 \%$ decrease in the diameter of the crystalline lens during accommodation in Rhesus monkeys, which is inconsistent with Tscherning's theory. More recently, investigators ${ }^{45}$ have reported a decrease in the diameter of the crystalline lens of $0.075 \mathrm{~mm}$ per dioptre of accommodation and a lens thickness increase of $0.064 \mathrm{~mm}$ per dioptre of accommodation. The role of the iris in 
helping to hold the anterior lens surface as suggested by the vitreous theorists ${ }^{28,41}$ has also been queried. Demonstrating that subjects with aniridia were capable of accommodating, Fincham ${ }^{20}$ showed that the iris does not play any significant role in accommodation.

\section{Coleman's theory of accommodation}

Until the time that Coleman proposed his theory of the mechanism of accommodation, the two dominant theories have been the 'capsular' relaxation theory proposed by Helmholtz ${ }^{21}$ and the vitreous lens (zonular contraction) theory originally proposed by Cramer $^{19}$ but described in details by Tscherning ${ }^{37,40}$ and Pflugk. ${ }^{41}$ Given the lack of concurrence between these theories, Coleman ${ }^{28}$ proposed a unified model for accommodation in 1970 which was referred to as the hydraulic suspension theory in $1986 .{ }^{46}$ In suggesting this new theory of accommodation, Coleman outlined some of the pathophysiological features that could not be explained by Helmholtz's capsular theory. These included the (1) rapid functional reproducibility of the optical surfaces of the lens, and the associated time constants of accommodative hysteresis, (2) potentiation of accommodation by convergence, (3) presbyopic reduction of accommodation, (4) forward translational movement of the lens during accommodation, (5) ability of the zonular-ciliary body attachment to flatten the lens without support from the vitreous and (6) relationship of accommodation to the progression of myopia and glaucoma. ${ }^{46,47}$ In the original unified model, Coleman ${ }^{28}$ argued that the vitreous prevents posterior polar movement of the crystalline lens. He described the vitreous as applying a force producing a change in catenary shape to the posterior lens surface, leading to changes in the anterior lens curvature. ${ }^{28}$ Coleman ${ }^{46}$ reported an experiment in which he demonstrated the increase in pressure in the vitreous when accommodation was stimulated with a concurrent decrease in pressure in the aqueous. He posited that the pressure differential between the vitreous and aqueous spaces acts as a hydraulic shift of the crystalline lens. He further showed that the aqueouscrystalline lens-vitreous system suspended by the zonular fibres could be likened to a catenary suspension. In this model, the release of tension on the zonular fibres (similar to the Helmholtz relaxation theory) will produce a steeper anterior lens curvature, with the vitreous resisting the posterior bulge of the lens.

Coleman's hydraulic suspension theory of accommodation is therefore an attempt to explain the respective roles played by the different anatomical structures involved in the accommodative mechanism. The model is consistent with a relaxed zonular fibre as postulated by the Helmholtz theory. In his model, Coleman stated that the ciliary body is the 'driving force for a predictable degree of accommodation' 46 and showed that his model explained certain physiological processes that could not otherwise be explained solely by the widely accepted Helmholtz capsular theory.

The role of the vitreous in accommodation has, however, been queried. ${ }^{48}$ Fisher $^{48}$ showed figures to demonstrate that there was no significant difference in the amplitude of accommodation measured in an eye with an intact vitreous and one without the vitreous (the subject having had a complete vitrectomy in that eye following persistent vitreous haemorrhage). On the basis of this clinical finding, he concluded that the vitreous is not essential for ocular accommodation nor for the forward displacement of the anterior pole of the crystalline lens in humans.

Martin et al. ${ }^{49}$ compared the results obtained using Coleman's hydraulic suspension theory of accommodation and Helmholtz's capsular theory to determine which of the two theories is more accurate in describing the mechanism of accommodation. They used finite element simulations of the lens and zonular fibres of 29- and 45 -year-old subjects. The refractive power change during accommodation obtained was consistent with Helmholtz's theory but inconsistent with Coleman's. In their findings, simulation by applying pressure to the posterior lens surface according to Coleman's theory did not result in any change in accommodation and therefore was not essential for the accommodation process. In comparison, simulation using Helmholtz's theory resulted in amplitude of accommodation that was comparable in magnitude to the measured amplitude of accommodation in human eyes. They concluded that, given the limitations and simplistic assumptions of the simulations, Helmholtz's theory gives a more accurate description of human accommodation than that of Coleman's theory.

\section{Schachar's theory of accommodation}

Schachar ${ }^{50,51}$ proposed an alternative theory for the accommodative process that bore a resemblance to Tscherning's theory of accommodation. According to Schachar, the ciliary muscle contracts during accommodation, leading to an increase in the tension of the equatorial zonular fibres which causes the central surface of the crystalline lens to steepen (increased convexity), the anterior-posterior diameter of the crystalline lens to increase, and the peripheral surfaces of the crystalline lens to flatten. Schachar's theory is that the equatorial zonular fibres play a dominant role in accommodation whilst the anterior and posterior fibres are passive in terms of structural support of the lens. Schachar's theory appears to bear a resemblance to Tscherning's theory in that both suggest that there is increased zonular fibre tension following ciliary muscle contraction during accommodation.

Schachar's theory is the basis for the surgical correction of presbyopia using sclera expansion rings ${ }^{52,53}$ and for which a USA patent has been issued. ${ }^{54}$

Schachar and $\mathrm{Bax}^{55}$ and other investigators ${ }^{56}$ have used mathematical models to support this theory of accommodation. Using nonlinear finite element analysis, Schachar and Bax ${ }^{55}$ and a more precise nonlinear differential equation model ${ }^{56}$ showed that the equatorial zonular fibres are in a state of increased tension during ocular 
accommodation, thus supporting Schachar's theory. They further concluded that the long-held Helmholtz theory of accommodation is not tenable. The effects of equatorial traction on an encapsulated biconvex deformable structure that has elliptical profiles similar to the crystalline lens were further used to support this theory. ${ }^{57,58,59,60}$ In direct opposition to the Helmholtz theory of accommodation, Schachar continued to perform experiments to validate his theory of accommodation. Applying tension to freshly extracted human crystalline lenses, he reported the topography of the effects of this zonular tension. ${ }^{61}$ He observed that zonular tension applied to the lens caused steepening of the central portion of the lens with peripheral flattening in accordance with his theory of accommodation, whilst zonular relaxation resulted in a central flattening and peripheral steepening of the crystalline lens - a clear opposite to what is predicted by Helmholtz's theory.

According to Schachar's theory, the lens equator is pulled towards the sclera by the increased equatorial zonular fibre tension. This position is not supported by Glasser and Kaufman ${ }^{62}$ who performed in vivo experiments using both electrical and pharmacological agents to stimulate accommodation in primates, and showed that the lens equator moves away from the sclera during accommodation and not towards it. They also revealed a downward sag of the lens as a result of gravity during accommodation.

\section{Conclusion}

Regarding the controversy surrounding the mechanism of accommodation, Helmholtz is reported to have said in 1866 that 'there is no other subject in physiological optics about which so many antagonistic opinions have been entertained as concerning the accommodation of the eye ${ }^{\prime} .{ }^{47}$ Given the various theories and the evidence supporting them, it appears that the debate on the mechanism of accommodation will continue until such time as imaging and other techniques are available to precisely study the accommodation process. Nevertheless, the Helmholtz theory is perhaps the most widely accepted mechanism for accommodation, despite the fact that it does not explain certain pathophysiological features associated with accommodation, such as the rapid functional reproducibility of the optical surfaces of the lens, and the associated time constants of accommodative hysteresis; the potentiating of accommodation by convergence; the presbyopic reduction of accommodation; the forward translational movement of the lens during accommodation; the ability of the zonularciliary body attachment to flatten the lens without support from the vitreous; and the relationship of accommodation to the progression of myopia and glaucoma.

\section{Acknowledgements}

This paper forms part of the work for the Doctor of Philosophy $(\mathrm{PhD})$ in Optometry at the University of KwaZulu-Natal undertaken by G.O. Ovenseri-Ogbomo under the supervision of Professor O.A. Oduntan.

\section{Competing interests}

The authors declare that they have no financial or personal relationships which may have inappropriately influenced them in writing this article.

\section{Authors' contributions}

The conception of the study, and the literature review, draft of the initial manuscript and approval of the manuscript was by G.O.O-O. (University of KwaZulu-Natal). Review of the initial draft, supervision of the study and approval of the manuscript was by O.A.O. (University of KwaZulu-Natal).

\section{References}

1. Daxecker F. Christopher Scheiner's eye studies. Doc Ophthalmol. 1992;81:27-35. http://dx.doi.org/10.1007/BF00155011

2. Scheiner C. Oculus hoc est: Fundamental opticum. Oeniponti (Innsbruck): Daniel Agricola; 1619.

3. Atchison DA, Charman WN. Thomas Young's contribution to visual optics: The Bakerian lecture 'On the mechanism of the eye'. J Vis. 2010;10:1-16. $\mathrm{http}: / / \mathrm{dx}$.doi.org/10.1167/10.12.16

4. Potterfield W. An essay concerning the motions of our eyes: Part 2. Of their internal motions. Edinburgh Med Essays Observations. 1738;4:124-294.

5. Hofstetter HW, Griffin JR, Berman MS, Everson RW. Dictionary of vision science and related clinical terms. Boston: Butterworth-Heinemann; 2000.

6. Ciuffreda KJ. Accommodation, the pupil and presbyopia. In: Benjamin WJ, editor. Borish's clinical refraction. Missouri: Butterworth-Heineman, 2006; p. 93-114. http://dx.doi.org/10.1016/B978-0-7506-7524-6.50009-0

7. Keirl A. Accommodation and presbyopia. In: Keirl A, Christie C, editors. Clinical optics and refraction. A guide for optometrists, contact lens opticians and dispensing opticians. London: Bailliere Tindall, 2007; p. 132-152.

8. Stein HA, Stein RM, Freeman MI, Massare JS. Ophthalmic dictionary and vocabulary builder for eye care professionals. London: Jaypee; 2012. http:// dx.doi.org/10.5005/jp/books/11479

9. Grosvenor T. Primary care optometry. St Louis: Butterworth-Heinemann; 2007.

10. Glasser A. Accommodation. In: Levin LA, Nilsson SF, Hoeve JV, Wu SM, editors. Adler's physiology of the eye. Oxford: Saunders, 2011; p. 40-70. http://dx.doi. org/10.1016/B978-0-323-05714-1.00003-0

11. Home E. The Croonian lecture on the mechanism employed in producing muscular motion. Phil Trans R Soc Lond. 1795;85:1. http://dx.doi.org/10.1098/ rstl.1795.0002

12. Atchison DA, Smith G. Optics of the human eye. Oxford: Butterworth-Heinemann, 2000; p. 64 .

13. Young T.The Bakerian lecture: On the mechanism of the eye. Phil Trans R Soc Lond. 1801;91:23-88. http://dx.doi.org/10.1098/rstl.1801.0004

14. Thorton SP, Doane JF. Understanding accommodation. Cataract and Refractive Surgery Today. 2005;September.

15. Descartes R. L'homme. Hall TS, translator. Cambridge, MA: Harvard University Press; 1633.

16. White JA. So-called accommodation in a lensless eye, with report of a case. Trans Am Ophthalmol Soc. 1897;8:241-244.

17. Davis AE. Accommodation in the lensless eye occurring in a woman aged seventy-three years, following extraction of cataract. Trans Am Ophthalmol Soc. 1919;17:444-460.

18. White JA. A case of accommodation in a lensless eye. Trans Am Ophthalmol Soc. 1920;18:272-274.

19. Cramer A. Het accommodatievermogen der oogen, physiologischtoegelicht. Haarlem: De Ervenloosjes Haarlem, 1853; p. 35-37.

20. Fincham EF. The mechanism of accommodation. $\mathrm{Br} J$ Ophthalmol. 1937; 8 (suppl):5-80.

21. Helmholtz HV. Uber die akkommodation des auges. A. v. Graefe's Arch Klin Ophthalmol. 1855;1:1-74. http://dx.doi.org/10.1007/BF02720789

22. Helmholtz HV. Helmholtz's treatise on physiological optics. Electronic edition, 2001: University of Pensylvania. Menasha: George Benta Publishing; 1924.

23. Hermans EA, Pouvels PJ, Dubbelman M, Kuijer JP, van der Heijde RG, Heethaar RM. Constant volume of the human lens and decrease in surface area of the capsular bag during accommodation: An MRI and Scheimpflug study. Invest Ophthalmol Vis Sci. 2009;50:281-289. http://dx.doi.org/10.1167/iovs.08-2124

24. Gullstrand A. Mechanism of accommodation. In: von Helmholtz $\mathrm{H}$, editor. Southhall JJPC, translator. Helmholtz's treatise on physiological optics. New York: Dover, 1909/1962; p. 383-415.

25. Gullstrand A. How I found the mechanism of intracupsular accommodation. Nobel lecture 11 December 1911. Nobel lectures, physiology or medicine 1901-1921. Amsterdam: Elsevier; 1911. 
26. Fisher RF. The significance of the shape of the lens and capsular energy changes in accommodation. J Physiol. 1969;210:21-47. http://dx.doi.org/10.1113/jphysiol. 1969.sp008740

27. Fisher RF, Pettet BE. The postnatal growth of the capsule of the human lens. Anat. 1972;112:207-214.

28. Coleman DJ. Unified model for the accommodative mechanism. Am J Ophthalmol. 1970;69:1063-1079. http://dx.doi.org/10.1016/0002-9394(70)91057-3

29. Manns F, Parel J-M, Denham D, et al. Optomechanical responses of human and monkey lenses in a lens stretcher. Invest Ophthalmol Vis Sci. 2007;48:3260-3268. $\mathrm{http}: / / \mathrm{dx}$.doi.org/10.1167/iovs.06-1376

30. Augusteyn RC, Mohamed A, Nankivil D, et al. Age-dependence of the optomechanical responses of ex vivo human lenses from India and the USA, and the force required to produce these in a lens stretcher: The similarity to in vivo disaccommodation. Vis Res. 2011;51:1667-1678. http://dx.doi.org/10.1016/j. visres.2011.05.009

31. Wan K-T, Ravi N. Mechanics of ocular accommodation consistent with the classical Helmholtz theory. Int J Exp Compl Biochem. 2009;1:193-203.

32. Lanchares $E$, Navarro R, Calvo B. Hyperelastic modelling of the crystalline lens: Accommodation and presbyopia. J Optom. 2012;5:110-120. http://dx.doi. org/10.1016/j.optom.2012.05.006

33. Glasser A, Wendt M, Ostrin L. Accommodative changes in lens diameter in Rhesus monkeys. Invest Ophthalmol Vis Sci. 2006;47:278-286. http://dx.doi. org/10.1167/iovs.05-0890

34. Wilson RS. Does the lens diameter increase or decrease during accommodation? Human accommodation studies: A new technique using infrared retroillumination video photography and pixel unit measurements. Trans Am Ophthalmol Soc. 1997; 95:261-270

35. Kasthurirangan S, Markwell EL, Atchison DA, Pope JM. MRI study of the changes in crystalline lens shape with accommodation and aging in humans. J Vis. 2011;11:19-35. http://dx.doi.org/10.1167/11.3.19

36. Jones CE, Atchison DA, Pope JM. Changes in lens dimensions and refractive index with age and accommodation. Optom Vis Sci. 2007;84:990-995. http://dx.doi. org/10.1097/OPX.0b013e318157c6b5

37. Tscherning M. Recherchers sur les changement optiques des l'oeil pendant accommodation. Arch de Physiol Norm et Pathol. 1895;7:158-180.

38. Strenk SA, Strenk LM, Koretz JF. The mechanism of presbyopia. Progress Ret Eye Res. 2005;24:379-393. http://dx.doi.org/10.1016/j.preteyeres.2004.11.001

39. Tscherning M. Physiological optics. Weiland C, translator. Philadelphia: Keystone, 1924; p. 192-228.

40. Tscherning M. Le mechanisme de I'accomodation. Ann Oculist Paris. 1904; 131:168-179.

41. Pflugk A v. Neue wege zur erforschung der lehre von der akkommodation. A v Graefe's Arch Ophthalmol. 1932;133:545-558.

42. Schneider H, Bacskulin A, Guthoff R. History of accommodation research. In: Guthoff R, Ludwig K, editors. Current aspects of human accommodation. In: Guthoff R, Ludwig K, editors. Current
Heidelberg: Kaden Verlag, 2001; p. 11-23.

43. Grossmann K. The mechanism of accommodation in man. Ophthalmol Rev. 1904;23:1-32.
44. Story JB. Aniridia: Notes on accommodation changes under eserine. Trans Ophthalmol Soc UK. 1924;44:413-417.

45. RichdaleK, SinnottLT, BullimoreMA, etal. Quantification of age relatedandperdiopter accommodative changes of the lens and ciliary muscle in the emmetropic human iovs.12-10619

46. Coleman JD. On the hydraulic suspension theory of accommodation. Trans Am Ophthalmol Soc. 1986;84:846-868.

47. Wilson SR. A new theory of accommodation: Cilio-zonular compression of the lens equator. Trans Am Ophthalmol Soc. 1993;91:401-419.

48. Fisher RF. Is the vitreous necessary for accommodation in man? Br J Ophthalmol. 1983;67:206. http://dx.doi.org/10.1136/bjo.67.3.206

49. Martin H, Guthoff R, Tarwee T, Schmitz K-P. Comparison of accommodation theories of Colman and of Helmholtz by finite element simulations. Vis Res. 2005;45:2910-2915. http://dx.doi.org/10.1016/j.visres.2005.05.030

50. Schachar RA. Zonular function: A new hypothesis with clinical implications. Ann Ophthalmol. 1994;26:36-38.

51. Schachar RA. The mechanism of accommodation and presbyopia. Int Ophthalmo Clin. 2006;46:39-61. http://dx.doi.org/10.1097/00004397-200604630-00006

52. Schachar RA. Cause and treatment of presbyopia with a method for increasing the amplitude of accommodation. Ann Ophthalmol. 1992;24:445-447.

53. Cross W. Theory behind surgical correction of prebyopia. Ophthalmol Clin North Am. 2001;14:315-333.

54. Schachar RA. Segmented scleral band for treatment of presbyopia and other eye disorders. Patent no. US 6197056 B1 USA, 2001.

55. Schachar RA, Bax AJ. The mechanism of human accomodation as analysed by nonlinear finite element analysis. Compr Therapy. 2001;27:122-132. http:// dx.doi.org/10.1007/s12019-996-0006-5

56. Chien $\mathrm{CH}$, Huang T, Schachar RA. Analysis of human crystalline lens accommodation. J Biomech. 2006;39:672-680. http://dx.doi.org/10.1016/j.jbiomech.2005.01.017

57. Fygenson DK, Marko JF, LibchaberA. Mechanics of microtubule-based membrane extension. Phy Rev Lett. 1997;79:4497-4500. http://dx.doi.org/10.1103/ PhysRevLett.79.4497

58. Schachar RA, Cudmore DP, Torti R, Black TD, Huang T. A physical model demonstrating Schachar's hypothesis of accommodation. Ann Ophthalmol. 1994 26:4-9.

59. Schachar RA, Fygenson DK. Topographical changes of biconvex objects during equatorial traction: An analogy of accommodation of the human lens. $\mathrm{Br}$ Ophthalmol. 2007;92:1698-1703. http://dx.doi.org/10.1136/bjo.2006.094888

60. Schachar RA, Cudmore DP, Black TD, et al. Paradoxical optical power increase of a deformable lens by equatorial stretching. Ann Ophthalmol. 1998;30:10-18.

61. Schachar RA. Qualitative effect of zonular tension on freshlyextracted intact human crystalline lenses: Implications for the mechanism of accommodation. Invest Ophthalmol Vis Sci. 2004;45:2691-2695. http://dx.doi.org/10.1167/iovs.03-1267

62. Glasser A, Kaufman PL. The mechanism of accommodation in primates. Ophthalmology. 1999;106:863-872. http://dx.doi.org/10.1016/S0161-6420(99) 00502-3 